\title{
DIFICULDADES DE APRENDIZAGEM NO CONTEXTO DAS PRODUÇÕES ACADÊMICAS BRASILEIRAS (2001-2011)
}

\section{LEARNING DISABILITIES IN THE CONTEXT OF BRAZILIAN ACADEMIC PRODUCTIONS (2001-2011)}

\author{
Elaine Cristina Bortolatto Serafin* \\ Universidade do Extremo Sul Catarinense, Pesquisadora do Grupo de Pesquisa sobre \\ Formação e Gestão na Educação Básica \\ Antonio Serafim Pereira** \\ Universidade do Extremo Sul Catarinense, Professor Pesquisador do Programa de \\ Pós-Graduação em Educação, Coordenador do Grupo de Estudos e Pesquisa sobre \\ Gestão e Formação na Educação Básica
}

Resumo: Neste trabalho, descreve-se o processo de pesquisa com o qual se objetivou analisar as concepções de dificuldades de aprendizagem nas produções acadêmicas em educação (2001-2011). O estudo possibilitou formular três ênfases temáticas: dificuldade de aprendizagem diferente de distúrbio ou transtorno, dificuldade como distúrbio ou transtorno e fatores implicados (intrínsecos e extrínsecos). A primeira sobressaiu-se na maioria das produções, nas quais autores concebem as dificuldades como temporárias, mais associadas ao contexto social (fatores extrínsecos), o qual, no entanto, tende a ser tomado como justificativa para confirmar o caráter patológico da dificuldade de aprendizagem diagnosticada.

Palavras-chave: Concepções de dificuldades de aprendizagem. Fracasso escolar. Ensino e aprendizagem.

\footnotetext{
* Mestre em Educação pela Universidade do Extremo Sul Catarinense; Especialista em Psicopedagogia Clínica e Institucional pela Escola Superior de Criciúma.

** Doutor em Educação pela Universidade de Santiago de Compostela, Espanha, reconhecido pela Universidade Federal de Goiás; Mestre em Educação pela Pontifícia Universidade Católica do Rio Grande do Sul.
} 
Abstract: In this work, it is described the research process by which we aimed to analyze the concepts of learning difficulties in academic productions in education (2001-2011). The study made it possible to formulate three thematic emphases: learning disability different from disturbance or disorder; difficulty as disturbance or disorder, and factors involved (intrinsic and extrinsic). The first excelled in most productions, in which authors conceive the difficulties as temporary, more associated to social context (extrinsic factors), which, however, tends to be taken as justification to confirm the pathological nature of learning disability diagnosed.

Keywords: Conceptions of learning disabilities. School failure. Teaching and learning.

\section{INTRODUÇÃO}

O tema da dificuldade de aprendizagem, na atualidade, em vista da ampliação do acesso à escola, especialmente no que diz respeito ao Ensino Fundamental, tem sido marcante nos diálogos entre professores, entre professores e gestores, e entre professores, gestores, pais e alunos. De um modo, esse tema pode ser traduzido em preocupação, intervenção positiva. De outro, insatisfação, justificativa, podendo ser expresso também em forma de preconceito, queixa e/ou encaminhamento.

Buscando compreender e refletir sobre as questões que envolvem as dificuldades de aprendizagem, decidimos desenvolver um estudo descritivo, de cunho bibliográfico, sobre concepções de dificuldades de aprendizagem, a partir das dissertações e teses brasileiras produzidas no período de 2001 a 2011.

Considerando nosso propósito, fizemos, inicialmente, uma busca on-line no Banco de Teses da Coordenação de Aperfeiçoamento de Nível Superior (Capes) (2015) e no site da Biblioteca Digital de Teses e Dissertações) (BDTD) (2015), utilizando o descritor dificuldades de aprendizagem e sua relação com o ensino, e foram encontrados 861 trabalhos acadêmicos para o período de 2001 a 2011.

Para filtrar a seleção, foram estabelecidos três critérios: apresentar no título dos trabalhos a palavra dificuldade de/na aprendizagem, ao qual, posteriormente, foram incorporadas as palavras concepções e perspectivas; estar relacionado à educação escolar no âmbito do Ensino Fundamental - anos iniciais e tratar-se de pesquisa na área da Educação. Atenderam a esses critérios, no período considerado, 16 dissertações e teses, das quais tivemos acesso a $12^{1}$, os quais foram submetidos à leitura na íntegra.

A pré-análise dos trabalhos permitiu agrupar os dados com temáticas semelhantes (categorias), os quais foram dispostos em quadros, visando à quantificação 
dos núcleos de sentido e à análise qualitativa dos dados emergentes no conjunto das produções (BARDIN, 2003). Desse procedimento, foi possível formular três categorias sobre dificuldades de aprendizagem, a saber: dificuldade de aprendizagem diferente de distúrbio ou transtorno, dificuldade de aprendizagem como distúrbio ou transtorno e fatores implicados nas dificuldades de aprendizagem (intrínsecos e extrínsecos à criança).

O presente trabalho descreve, brevemente, a história do pensamento sobre dificuldades de aprendizagem, com destaque para as perspectivas atuais recorrentes na literatura especializada. Na sequência, apresentam-se e discutem-se os resultados que emergiram deste estudo no diálogo com os autores de referência.

\section{ESTUDOS INICIAIS SOBRE DIFICULDADES DE APRENDIZAGEM}

Possivelmente, em qualquer tempo e lugar, existiram (e existem) crianças que apresentaram dificuldades de aprendizagem no âmbito da educação escolar. Segundo Sisto (2001), os estudos sobre o tema das dificuldades de aprendizagem se iniciaram por volta de 1800, tendo como responsável o médico alemão Franz Joseph Gall, o qual trabalhava com indivíduos que apresentavam lesão cerebral (afasia); para ele, apesar de a lesão afetar a fala, a inteligência não era prejudicada.

Todavia, conforme Sisto (2001), somente em 1963 chegou-se a um certo consenso sobre o termo, demarcando, assim, o campo das dificuldades de aprendizagem. Segundo o autor, o psicólogo americano Samuel A. Kirk associou as dificuldades de aprendizagem a problemas escolares. Na época, ao criar o termo, Learning Disabilities (Dificuldades de Aprendizagem), Samuel A. Kirk se referia a um atraso ou desordem em um ou mais processos da fala, leitura, escrita ou matemática não associados à deficiência mental ou à privação sensorial ou cultural. Desse modo, o enfoque médico (patológico) dado às dificuldades de aprendizagem cedeu lugar a uma nova abordagem: a psicoeducacional, que buscava passar às crianças explicações e informações sobre seu problema, ajudando-as a lidar com a dificuldade apresentada.

Após 1963, ampliam-se os debates em torno dos conceitos de dificuldades de aprendizagem, contribuindo para o desenvolvimento de pesquisas sobre o tema em Educação, Psicologia, Neurologia, Linguística, entre outras áreas.

Segundo Dornelles (2000), a abordagem das dificuldades de aprendizagem surge, mais efetivamente, na década de 1980. Nessa época, iniciou-se uma reflexão 
sobre o papel da escola na questão das dificuldades, considerando o avanço dos estudos e pesquisas sobre o assunto em uma perspectiva histórico-cultural.

\subsection{CONCEPÇÕES DE DIFICULDADES DE APRENDIZAGEM}

Entre as concepções de dificuldade de aprendizagem presentes na literatura especializada, Martinelli (2001) destaca o conceito norte-americano da National Joint Committee of Learning Disabilities (NJCLD), de 1988, que se tornou referência para pesquisas e estudos na área, a saber:

Dificuldades de aprendizagem é um termo genérico que diz res-
peito a um grupo heterogêneo de desordens manifestadas por
dificuldades significativas na aquisição e uso das capacidades
de escuta, fala, leitura, escrita, raciocínio ou matemáticas. Essas
desordens são intrínsecas ao indivíduo e são devidas presumi-
velmente a uma disfunção do sistema nervoso central. Embora
as dificuldades de aprendizagem possam ocorrer concomitante-
mente com outras condições de incapacidade (por exemplo, pri-
vação sensorial, deficiência mental, perturbação emocional ou
social) ou influências ambientais (por exemplo, diferenças cul-
turais, ensino insuficiente/inadequado, fatores psicogenéticos),
não são devidas a tais condições ou influências. (NATIONAL
JOINT COMMITTEE OF LEARNING DISABILITIES, 1994,
p. 65-66 apud MARTINELLI, 2001, p. 107-108).

Como se percebe, essa definição de dificuldades de aprendizagem tem base neurobiológica, atribuindo as causas de tais dificuldades ao indivíduo. Isso significa dizer que mesmo que a criança apresente dificuldades de aprendizagem e esta ocorra concomitantemente a outras condições (socioculturais, sensoriais, intelectuais, pedagógicas), a “desordem” ainda seria intrínseca ao indivíduo.

Nessa mesma perspectiva, podemos citar o Código Internacional de Doenças (2000) e o Manual Diagnóstico e Estatístico de Transtornos Mentais (2002). Ambos os manuais classificam as dificuldades de aprendizagem como transtornos, que podem persistir até a idade adulta, sendo diagnosticadas por meio de testes padronizados (administração individual) de leitura, matemática, motricidade, expressão escrita, entre outros, cujos resultados acusarão níveis de desempenho abaixo do esperado para a idade, escolarização e grau de inteligência do indivíduo. O chamado Transtorno de Déficit de Atenção e Hiperatividade (TDAH), de ordem comportamental, está incluso nessa compreensão.

Por esse prisma, as causas dos transtornos de aprendizagem são intrínsecas ao aluno, originadas por condições anormais no processo de desenvolvimento do 
sistema nervoso central. Segundo Pelegrini e Golfeto (2000, p. 37), essas condições decorrem, geralmente, de algum tipo de disfunção biológica; para eles, “[...] são manifestadas por comprometimentos específicos e significativos no aprendizado de habilidades escolares." Nesse caso, as dificuldades de aprendizagem ocorrem em razão de alteração cerebral e são consideradas "[...] um transtorno relacionado à linguagem - fala, compreensão, leitura, soletração -, causado neurologicamente e produto de uma rede complexa de interações sociais." (SISTO, 2001, p. 24).

$\mathrm{Na}$ perspectiva de transtorno de base neurobiológica, a dificuldade de aprendizagem e o fracasso dela resultante recaem sobre a criança e/ou sobre seu meio social imediato (a família), que passam a ser responsabilizados pela situação evidenciada. Entre os fatores genéticos e sociais, vinculados à criança, podem ser considerados, conforme José e Coelho (2004), a idade, a constituição física, o desenvolvimento, o ambiente cultural, a conduta e a personalidade familiar, os traumas e a influência de pressões externas e internas.

Essa visão "mascara" o real problema, que vai além das dificuldades. Desse modo, a sustentação do posicionamento neurobiológico desconsidera o contexto social no qual as dificuldades são produzidas. Nesse caso, podemos pensar no próprio sistema educacional que, muitas vezes, confirma o diagnóstico de anormalidade ou de doença atribuída ao aluno, patologizando o processo de ensino e aprendizagem, como afirmam Collares e Moysés (1996).

Tal perspectiva tem alimentado os encaminhamentos clínicos de alunos a médicos e especialistas das áreas da educação e saúde, que tendem a reforçar o caráter terapêutico das dificuldades de aprendizagem. Tais encaminhamentos têm desencadeado, na compreensão de Meira (2012), uma epidemia de diagnósticos, produzindo, na mesma escala, uma epidemia de tratamentos medicamentosos, especialmente nos casos de TDAH. Esse aumento na medicalização é fator preocupante, uma vez que a Ritalina, ${ }^{2}$ segundo Eidt (2014, p. 3), proporciona uma "solução mágica”, e “[...] muitos professores esquecem que o remédio não educa e, tampouco, promove o processo de humanização."

O distúrbio de aprendizagem, outra concepção de dificuldade de aprendizagem encontrada na literatura, configura-se no mesmo grupo de transtorno ou dificuldade específica, por apresentar as mesmas características, ou seja, corresponde a disfunções do sistema nervoso central. Ciasca (2003, p. 22-23) define o termo distúrbio como "[...] uma perturbação ou falha na aquisição e utilização de informações ou na habilidade para solução de problemas", que não implica incapacidade, mas dificuldade de aprendizagem, podendo estar relacionada a distúrbios emocionais, sociais, alterações sensoriais ou deficiência intelectual. Somente haverá incapacidade de aprender 
quando houver lesão cerebral grave (afasias, agnosias, apraxias, alexias, agrafias e acalculias), como afirma Fonseca (2009), ou ainda, paralisias cerebrais, epilepsia e deficiência mental, além de envolver também os sistemas sensoriais (audição e visão), como ressalta Ballone (2013).

A dificuldade de aprendizagem compreendida dessa forma tem legitimado a ideia de que a criança tem dificuldade e/ou fracassa no seu processo de aprendizagem porque apresenta déficit de cognição e ainda é tida como preguiçosa, desatenta ou carente $\mathrm{e}$, por isso, prognosticada como candidata à reprovação, como denunciam Pereira (1996), Dornelles (2000) e Patto (2010).

Atualmente, contrapondo-se a essa concepção neurobiológica, vêm se destacando alguns estudos, entre eles os de Martinelli (2001) e os de Fonseca (2009), que consideram a dificuldade de aprendizagem uma alteração transitória, que pode ser acompanhada de forma pedagógica e psicopedagógica, com intervenções com os pais e a escola, considerando-se fatores ambientais ou escolares insatisfatórios/inadequados.

Tal perspectiva se relaciona à visão dialética de Vygotsky (1997), a qual considera o contexto sócio-histórico da criança no processo de apropriação do conhecimento. Para o autor, toda criança é capaz de aprender, mesmo possuindo déficit, ou seja, dificuldade de aprendizagem. Nessa visão, o conceito de zona de desenvolvimento proximal, no que se refere à diferença de crianças que não apresentam e que apresentam dificuldades de aprendizagem, assume vital importância. As crianças que não apresentam dificuldades demonstram independência na resolução de problemas; as que apresentam dificuldades precisarão de ajuda específica de um adulto ou colega mais experiente para lograr desempenho de aprendizagem conforme os objetivos esperados para o nível de ensino em que se encontram. Assim, as ações de interação promovidas possibilitarão novas oportunidades de aprendizagem para essas crianças.

A partir disso, observa-se a importância de o processo de interação acontecer de modo que o professor encaminhe o ensino para a capacidade máxima de seus alunos, uma vez que a aprendizagem deve ser o resultado do ensino. Na concepção de Facci (2004, p. 230), o ato de ensinar não pode ser vazio e tem sua peculiaridade, isto é, consiste em “"[...] firmar o acesso do aluno a uma nova realidade, a um novo conhecimento sistematizado, assim como levá-lo ao domínio de cada componente da nova atividade."

Entretanto, a forma como as dificuldades de aprendizagem são identificadas no cotidiano escolar como problemas, dificuldades, distúrbios e também transtornos - sem distinção - pode confundir e frustrar os educadores. Confundir no sentido de estes não compreenderem os conceitos, e frustrar por não encontrarem soluções 
para os problemas dos alunos, como afirmam Tafner e Fischer (2001, p. 31): "Por muitos anos, tais crianças têm sido ignoradas, mal diagnosticadas e maltratadas. A dificuldade de aprendizagem vem frustrando a maior parte dos educadores, pois na maioria das vezes não encontram solução para tais problemas." Sobre essa discussão, vale aludir à sistematização de Moojen e França (2006), quando tratam do diagnóstico psicopedagógico, objetivando minimizar as confusões terminológicas que podem acontecer no âmbito da temática em pauta.

Essa situação no ambiente escolar tem servido historicamente para a construção social das dificuldades de aprendizagem, produzindo acertos, desacertos e, principalmente, grandes desafios, entre eles, os que dizem respeito à superação do fracasso escolar. Por isso, a forma como as dificuldades de aprendizagem são vistas no ambiente escolar, via de regra, como transtorno ou distúrbio (culpabilizando o aluno/ família pelo seu fracasso), precisa ser superada. Segundo Collares e Moysés (1996), essa concepção é pragmática, desenvolvendo preconceitos prévios sobre as crianças que não aprendem, especialmente, as marginalizadas pela sociedade, como as pobres, as negras, as nordestinas, entre outras. Costa (1994) propõe desmistificar essa concepção pseudopatológica a partir de um olhar mais crítico, que considere o conjunto das dimensões (orgânicas, cognitivas, emocionais, sociais e pedagógicas) do contexto no qual o aluno está inserido.

Para Souza (1995), ao atribuir a culpa dos problemas de aprendizagem somente ao aluno e, por extensão, à sua família, a escola se exime da responsabilidade no processo escolar. Segundo a autora, é preciso aproximar alunos, pais e professores, a fim de refletirem sobre os aspectos que atrapalham a vida escolar, para que se possa superar as dificuldades e lutar por uma escola de qualidade.

\section{APRESENTANDO E DISCUTINDO OS DADOS}

Inicialmente, consideramos importante sublinhar que: a maioria das dissertações e teses analisadas (60\%) é originária de universidades paulistas; a concentração de maior produção acadêmica sobre dificuldades de aprendizagem, no período considerado, ocorreu no ano 2007, seguido dos anos 2003, 2004, 2008 e 2011, com igual índice de pesquisa; a incidência das pesquisas recaiu sobre os professores e/ou profissionais da área da Educação e sobre o $3^{\circ}$ ano do Ensino Fundamental, considerado o final do ciclo da alfabetização; a preponderância dos autores citados concentrou-se em Jean Piaget, seguido de Lev S. Vygotsky, deixando evidente a preferência pela concepção genético-cognitivista, que tem o primeiro autor como teórico principal. Como 
veremos adiante, esses autores têm influenciado a discussão sobre aprendizagem e, consequentemente, sobre a dificuldade dela decorrente.

Do conteúdo das produções analisadas, foi possível captar as concepções de dificuldades de aprendizagem e os fatores nelas implicados. No que se refere às concepções, a análise se desenvolveu em dois focos: dificuldades de aprendizagem diferente de distúrbio ou transtorno e dificuldades de aprendizagem como distúrbio ou transtorno. Os fatores implicados, por sua vez, foram tomados nas duas dimensões mencionadas anteriormente: intrínseca e extrínseca à criança.

\subsection{DIFICULDADE DE APRENDIZAGEM DIFERENTE DE DISTÚRBIO OU TRANSTORNO}

A concepção que diferencia dificuldade de distúrbio ou transtorno predominou nos trabalhos analisados: de 12 dissertações e teses, oito produções (T1, T2, T4, T5, T6, T9, T11, T12) ${ }^{3}$ consideram que as dificuldades não estão associadas a fatores orgânicos ou neurológicos (intrínsecos à criança). As citações a seguir de dois trabalhos analisados ilustram essa posição: "As dificuldades de aprendizagem são decorrentes de problemas psicopedagógicos e/ou socioculturais, ou seja, o problema não estaria na criança.” (T4) (OSTI, 2004, p. 55). "Atualmente já é aceita a ideia da existência de crianças que não aprendem, embora não possuam nenhum comprometimento mental.” (T1) (CRUZ, 2003, p. 29).

Para esse grupo de autores, as dificuldades de aprendizagem são temporárias, uma vez que a criança possui inteligência dentro dos padrões de normalidade, está inserida em um processo de ensino adequado, é interessada e motivada em aprender e não apresenta comprometimentos visuais ou auditivos, como destaca Fonseca (2009). Conforme Martinelli (2001), essas dificuldades podem ser tratadas com acompanhamento pedagógico e psicopedagógico, considerando-se os fatores familiares, socioculturais e pedagógicos, conduzindo o aluno ao processo normal de aprendizagem. Para Ballone (2013), essas dificuldades podem ser consideradas primárias, visto que não possuem elementos neurobiológicos em sua origem.

Cabe ressaltar que nosso posicionamento se filia a esse grupo de autores, entendendo dificuldades de aprendizagem como alterações transitórias e reversíveis, manifestadas na vida escolar, sem comprometimentos neurobiológicos e sensoriais, tratados com acompanhamento pedagógico e psicopedagógico.

Tal concepção se aproxima das perspectivas genético-cognitiva, de Piaget (1975, 1993), e dialética, de Vygotsky (1991, 1997, 2001), por considerarem o meio 
social no processo de aprendizagem e desenvolvimento. Embora para esses dois teóricos o processo tenha características diferentes, ambos visualizam a importância do meio social, que influencia, positiva ou negativamente, a relação educacional. Para que a influência seja positiva, o meio deve oferecer oportunidades que visem superar as dificuldades apresentadas pela criança decorrentes de problemas emocionais, motivacionais e até mesmo do próprio ensino.

\subsection{DIFICULDADE DE APRENDIZAGEM COMO DISTÚRBIO OU TRANSTORNO}

A concepção de que as dificuldades de aprendizagem correspondem a distúrbios ou transtornos apareceu em quatro dos 12 trabalhos analisados (T3, T7, T8, T10). Embora as quatro produções acadêmicas tenham se referido às dificuldades de aprendizagem de forma particular (áreas de expressão oral e escrita, leitura e compreensão, cálculo e raciocínio lógico matemático), elas direcionaram os conceitos de dificuldades de aprendizagem na perspectiva de distúrbio ou transtorno, como expressa o T10 (RAUPP, 2008, p. 29):

Dificuldades de aprendizagem é um termo geral que se refere a um grupo heterogêneo de desordens manifestadas por más estruturações significativas na aquisição e utilização da compreensão auditiva, da fala, da escrita e do raciocínio matemático. Essas desordens são intrínsecas ao indivíduo.

Dessa forma, as dificuldades de aprendizagem originam-se na própria criança (base neurobiológica), ou seja, as causas de tais dificuldades são atribuídas à criança. A dificuldade de aprendizagem é vista, então, como anormalidade no processo cognitivo, relacionada ao mau funcionamento do sistema nervoso central, manifestando comprometimento específico e significativo no aprendizado escolar, originando disfunções como disgrafia, disortografia, discalculia, dislexia, dispraxia, disfasias e disgnosias. Essas disfunções não implicam incapacidades de aprendizagem, ocorrem somente quando há lesão cerebral, como destacam Pellegrini e Golfeto (2000), Ballone (2003), Ciasca (2003), entre outros autores.

Essa concepção se baseia no conceito norte-americano da National Joint Committee of Learning Disabilities (NJCLD), de 1988, de que as dificuldades de aprendizagem dizem respeito a um grupo heterogêneo de desordens manifestadas por dificuldades na aquisição e no uso das capacidades de escuta, fala, leitura, escrita, raciocínio ou matemática. 
Por esse prisma, a dificuldade de aprendizagem assume caráter patológico intrínseco à criança. Os manuais, entre eles o CID 10 (CLASSIFICAÇÃO INTERNACIONAL DE DOENÇAS, 2000) e o DSM.IV (MANUAL DIAGNÓSTICO E ESTATÍSTICO DE TRANSTORNOS MENTAIS, 2002), também tratam as dificuldades de aprendizagem dessa forma. Esse entendimento reforça a visão patológica da dificuldade, considerada uma imaturidade do sistema cognitivo do aluno.

Os autores analisados (dissertações e teses), no entanto, não se mostraram favoráveis à essa visão patológica, ou à ideia de buscar culpados para o problema das dificuldades de aprendizagem, como demonstra o T10 ao afirmar: "[...] acredito que os professores são agentes transformadores ou patologizantes de alguns alunos." "Já virou rotina o encaminhamento dos alunos com dificuldades de aprendizagem a especialistas.” (RAUPP, 2008, p. 65, 73). Essa posição também foi reafirmada por Meira (2012) e Eidt (2009), ao alertarem para a epidemia de diagnósticos realizados por médicos e especialistas, levando a tratamentos medicamentosos os quais, em certos casos, são desnecessários. Tais procedimentos, muitas vezes, desconsideram o contexto no qual as dificuldades são produzidas.

Nessa mesma direção, o T3 (SCHIAVONI, 2004, p. 14) enfatiza que as crianças com distúrbios de aprendizagem são, geralmente, as que mais chamam a atenção dos professores, sendo consideradas pouco inteligentes, e alerta: "[...] o mais grave é que, na maioria das vezes, essas considerações implicam na crença de uma incapacidade para aprender."

Para os autores analisados, a compreensão das dificuldades de aprendizagem nessa perspectiva se deve à inconsistência teórica do professor sobre o assunto, decorrente de sua formação inicial. A consequência é o seu despreparo para rever conceitos e reavaliar o processo de ensino e aprendizagem de forma crítico-reflexiva sobre as dificuldades de aprendizagem, como destacam Pereira (1996) e Dornelles (2000).

\subsection{FATORES IMPLICADOS NAS DIFICULDADES DE APRENDIZAGEM: QUESTÕES INTRÍNSECAS E EXTRÍNSECAS À CRIANÇA}

Nessa categoria, discutimos os sentidos correspondentes aos fatores implicados nas dificuldades de aprendizagem, tendo como referência os resultados e conclusões descritos nos trabalhos acadêmicos analisados.

Ressalvadas as diferenças de concepções encontradas nos trabalhos, relativas às dificuldades de aprendizagem, todos os autores, a princípio, referiram-se a 
fatores implicados nesse processo. Isso significa dizer que, para os autores dos trabalhos analisados, as dificuldades de aprendizagem podem estar relacionadas a fatores intrínsecos e extrínsecos à criança, tendo como consequência o fracasso escolar. É claro que ao indicar tais fatores não perdemos de vista a ideia de que as dificuldades de aprendizagem são fenômenos multifacetados e complexos para as quais podem concorrer, simultaneamente, vários fatores.

No que se refere aos fatores intrínsecos à criança, as produções acadêmicas destacaram, entre outros, os aspectos físicos, emocionais, cognitivos e biológicos. Em relação aos fatores extrínsecos, os aspectos social, familiar e educacional aparecem com abordagem diferenciada, conforme a visão de déficit ou cultural.

\subsubsection{Fatores intrínsecos à criança}

Os resultados e conclusões dos trabalhos analisados confirmam a concepção, ainda prevalente entre professores e/ou profissionais da educação, de que as dificuldades podem ser originadas somente por fatores internos à criança. Segundo os autores, essa postura se configurou nos ambientes escolares pesquisados em uma visão sintomática de doença e de dores físicas, com alterações orgânicas e neurológicas, geradoras de déficit cognitivo e intelectual com carência nas seguintes áreas: atenção, memória, compreensão, motivação, interesse, autoconceito, entre outras. Servem para ilustrar essa posição os resultados dos trabalhos 4: "Nesse ponto, as dificuldades são vistas como indicador de algo errado, sintomático, assemelhando-se à visão de doença, por isso a necessidade de um especialista, pois só ele pode conseguir a cura" (OSTI, 2004, p. 63), e T5: "Os professores demonstram uma imagem que expressa a relação entre doença e dificuldades de aprendizagem, ou seja, o aluno não aprende por ter problemas de saúde, remetendo a questões cognitivas ou pessoais." (COLUS, 2006, p. 154).

Essa concepção, segundo os autores analisados, difere da posição teórica adotada em seus trabalhos, uma vez que a maioria deles considera dificuldade de aprendizagem diferente de doença, tomando o fracasso escolar como resultante de anormalidade do processo cognitivo. Nesse sentido, o autor do T11 alerta: "O encaminhamento ao médico ratifica que a ideia patologizante sobre as dificuldades de aprendizagem ainda está bem presente no ambiente escolar." (PEREIRA, 2011, p. 125). Essa compreensão tem contribuído para disfarçar as verdadeiras dificuldades de aprendizagem, culpabilizando a criança pelo seu baixo rendimento ou fracasso escolar, como destacam Souza (1995), Collares e Moysés (1996), Dorneles (2000) e Patto 
(2010), e desconsiderando os fatores externos, entre eles a escola, os quais podem contribuir, positiva ou negativamente, para esse processo.

Aqui reside a associação da dificuldade de aprendizagem à medicalização, que figura, muitas vezes, como medida paliativa ou "mágica" para a solução das dificuldades de aprendizagem. Essa é uma questão que merece aprofundamento e reflexão.

\subsubsection{Fatores extrínsecos à criança}

Quanto aos fatores implicados nas dificuldades de aprendizagem, referentes às questões extrínsecas à criança, todos os trabalhos concluíram que os aspectos familiar, social e educacional se refletem no diagnóstico das dificuldades de aprendizagem, como ilustra o T8: "A maior quantidade de argumentos dos professores, em relação às dificuldades de aprendizagem dos alunos, está relacionada aos fatores externos." (CAMPOS, 2007, p. 143). No entanto, importa destacar que os fatores externos analisados nas obras assumem dois posicionamentos diferenciados: o primeiro refere-se à visão de déficit e o segundo, à visão cultural.

$\mathrm{Na}$ visão de déficit, as dificuldades de aprendizagem são atribuídas diretamente ao aluno e ao seu contexto imediato. Nesse caso, suas famílias são tidas como desestruturadas e descomprometidas, como é expresso no T5: "Ao se ter a família do educando com dificuldade de aprendizagem como referência, verificou-se que o conceito reproduzido em imagem nos relatos foi o desamparo." (COLUS, 2006, p. 120). Tal conceito passa a se constituir em rótulos, recaindo, na maioria das vezes, sobre as famílias menos favorecidas socioeconomicamente.

Sabe-se da importância do papel da família na constituição de um adulto responsável, entretanto, apesar de a questão familiar contribuir para a análise e compreensão das dificuldades de aprendizagem, esse aspecto isolado não pode ser critério para diagnosticar tais dificuldades, considerando-se que os problemas familiares estão presentes também em crianças sem dificuldades de aprendizagem.

Outro fator que reforça a visão de déficit é o aspecto socioeconômico da família. Segundo os autores analisados, essa visão produz o estereótipo de que aluno pobre tem dificuldade de aprendizagem, isentando a escola da sua responsabilidade social no processo de ensino e aprendizagem, desconsiderando ou secundarizando os aspectos sócio-históricos, reafirmados por Patto (2010).

Na perspectiva de déficit, a denúncia preponderante nos trabalhos analisados recai sobre o discurso dos professores, que desobriga a escola quando se trata de dificuldades de aprendizagem, como destacam Costa (1994), Souza (1995), Collares 
e Moysés (1996), Dorneles (2000) e Patto (2010). Isso ocorre, muitas vezes, pelo fato de que o professor estabelece padrões de desempenho escolar, como, por exemplo: "modelo de aluno normal" e/ou "sala homogênea", geralmente frutos da sua formação e cultura escolar. Em outras situações surge a frustação por não encontrar solução para tais dificuldades, seja por confusão de conceitos ou por desconhecimento do problema. Nesse sentido, o T11 assim se expressa: “A falta de tomada de consciência, por parte do professor, em relação a aspectos fundamentais de sua ação docente, gera no aluno e no sistema educacional problemas graves, como o fracasso escolar, até mesmo consequências irreparáveis." (PEREIRA, 2011, p. 72).

Nesse caso, segundo os autores analisados, o fracasso escolar ocorre em razão de diferentes fatores: despreparo dos professores para ensinar (problemas de didática, linguagem e postura); diagnósticos apressados; conteúdos curriculares desconectados da realidade do aluno; avaliação inadequada/pouco consistente; recursos pedagógicos precários; omissão da escola quanto aos aspectos anteriores, entre outros, como ilustram as seguintes passagens: "A dificuldade para aprender pode estar relacionada a fatores externos, como a metodologia de ensino, recursos didáticos e a própria postura do professor em sala de aula." (T4) (OSTI, 2004, p. 62). “Os professores não fazem nenhum tipo de relação entre as dificuldades de aprendizagem e seus métodos de ensino." (T10) (RAUPP, 2008, p. 73).

Em oposição a essa visão de déficit, situam-se os autores que defendem a perspectiva sócio-histórico-cultural no estudo e a discussão das dificuldades de aprendizagem, considerando a contribuição do meio familiar, educacional e social, sem se descuidar dos fatores internos do próprio sujeito que aprende, no processo de produção e apropriação do conhecimento por parte do aluno (VYGOTSKY, 1991, 1997, 2001).

\section{CONSIDERAÇÕES FINAIS}

Conforme descrito, das produções acadêmicas analisadas, emergiram duas concepções de dificuldades de aprendizagem: dificuldade de aprendizagem diferente de distúrbio ou transtorno e dificuldade de aprendizagem como distúrbio ou transtorno, bem como os fatores implicados nessas dificuldades (intrínsecos e extrínsecos à criança).

A concepção que entende as dificuldades de aprendizagem como distúrbio ou transtorno, centrada nos fatores intrínsecos (na própria criança ou seu contexto imediato), figurou na minoria dos trabalhos, suplantada pela visão de que as dificuldades são diferentes de distúrbio ou transtorno de aprendizagem, isto é, são temporárias ou primárias, por isso podem ser tratadas com acompanhamento pedagógico e psico- 
pedagógico, considerando-se os fatores familiares, socioculturais e pedagógicos, de modo a conduzir o aluno ao processo normal de aprendizagem.

Quanto aos fatores implicados, os extrínsecos (presentes na maioria dos trabalhos) assumem duas perspectivas: a de déficit e a cultural. Os trabalhos analisados denunciam que a perspectiva de déficit continua prevalente no contexto escolar. Desse modo, faz-se necessário rever conceitos e discursos sobre as dificuldades de aprendizagem, especialmente nessa visão, que tende a eximir a escola da responsabilidade no processo de aprendizagem do aluno, como destacam Costa (1994), Souza (1995), Collares e Moysés (1996), Dorneles (2000) e Patto (2010).

Pelo exposto, consideramos importante investir na formação docente, inicial e continuada, em uma perspectiva histórico-cultural (VYGOTSKY, 1991, 1997, 2001), no sentido de contribuir para a compreensão teórica e prática das questões que envolvem as dificuldades de aprendizagem no contexto escolar. Afinal, os trabalhos analisados reafirmam essa necessidade.

De nossa parte, consideramos que o desenvolvimento de pesquisa empírica nos permitirá ampliar e aprofundar os resultados obtidos na pesquisa bibliográfica empreendida, favorecendo-nos avançar na compreensão da problemática que envolve as dificuldades de aprendizagem no cotidiano das escolas de Ensino Fundamental, especialmente de nossa região. Concretizá-la, eis um de nossos próximos desafios.

Notas explicativas:

${ }^{1}$ Nove dissertações de Mestrado e três teses de Doutorado em Educação.

${ }^{2}$ Medicação à base de metilfenidato (substância química estimulante do sistema nervoso central).

${ }^{3}$ As dissertações e teses são identificadas por $\mathrm{T}$ (trabalho), seguido de número correspondente à ordem de análise.

\section{REFERÊNCIAS}

BALLONE, G. J. Dificuldades de aprendizagem. 2003. Disponível em: <http:// www.psiqweb.med.br/site/?area $=\mathrm{NO} /$ LerNoticia\&idNoticia=30>. Acesso em: 28 out. 2013.

BARDIN, L. Análise de conteúdo. Tradução Luís Antero Reto e Augusto Pinheiro. Portugal: Edições 70, 2003.

BIBLIOTECA DIGITAL DE TESTES E DISSERTAÇÕES. Conhecimento e reconhecimento. Pesquisa científica do Brasil. Disponível em: $<$ http://bdtd.ibict.br/>. Acesso em: 13 mar. 2013. 
CAMPOS, E. G. J. As dificuldades de aprendizagem da divisão: análise da produção de erros de alunos do ensino fundamental e sua relação com o ensino praticado pelos

professores. 2007. 220 p. Dissertação (Mestrado em Educação)-Universidade Católica Dom Bosco, Campo Grande, 2007.

CARVALHO, M. G. Q. O professor e as dificuldades de aprendizagem: concepções e práticas. 2007. 163 p. Dissertação (Mestrado em Educação)-Universidade de Católica de Goiás, Goiânia, 2007.

CIASCA, S. M. Distúrbios e dificuldades de aprendizagem: questão de nomenclatura. In: CIASCA, S. M. (Org.). Distúrbios de aprendizagem: proposta de avaliação interdisciplinar. São Paulo: Casa do Psicólogo, 2003.

CLASSIFICAÇÃO INTERNACIONAL DE DOENÇAS. CID 10. Tradução Centro Colaborador da Organização Mundial da Saúde. São Paulo: Ed. USP, 2000.

COLlARES, C. A. L.; MOYSÉS, M. A. A. Preconceitos no cotidiano escolar: ensino e medicalização. São Paulo: Cortez, 1996.

COLUS, F. A. M. Construção social das dificuldades de aprendizagem. 2006. 185 p. Dissertação (Mestrado em Educação)-Centro Universitário Moura Lacerda, Ribeirão Preto, 2006.

COORDENAÇÃO DE APERFEIÇOAMENTO DE PESSOAL DE NÍVEL SUPERIOR. Banco de testes. Disponível em: <http://capesdw.capes.gov.br/capesdw/>. Acesso em: 25 abr. 2013.

COSTA, D. A. F. Fracasso escolar: diferença ou deficiência? Porto Alegre: Kuarup, 1994.

CRUZ, S. A. B. O professor diante das dificuldades de aprendizagem de seus alunos: concepções e intervenção. 2003. 135 p. Dissertação (Mestrado em Educação)-Faculdade de Ciências e Letras da Universidade Estadual Paulista Júlio de Mesquita Filho, Araraquara, 2003.

DELL'AGLI, B. A. V. Aspectos afetivos e cognitivos da conduta em crianças com e sem dificuldades de aprendizagem. 2008. 306 p. Tese (Doutorado em Educação)-Faculdade de Educação da Universidade Estadual de Campinas, Campinas, 2008.

DORNELES, B. V. As várias faces do caleidoscópio: anotações sobre o fracasso escolar. Pátio, Porto Alegre: Artmed, v. 3, n. 11, p. 25-28, jan. 2000. 
EIDT, N. M. O desenvolvimento cultural da atenção: contribuições para a superação do processo de medicalização da infância. In: ENCONTRO NACIONAL DA ABRAPSO, 15., 2009, Maceió. Anais... Maceió, 2009. Disponível em: <http://www. abrapso.org.br/siteprincipal/images>. Acesso em: 22 jun. 2014.

FACCI, M. G. D. Valorização ou esvaziamento do trabalho do professor?: um estudo critico-comparativo da teoria do professor reflexivo, do construtivismo e da psicologia vygotskyana. Campinas: Autores Associados, 2004.

FONSECA, V. da. Cognição, neuropsicologia e aprendizagem: abordagem neuropsicológica e psicopedagógica. 4. ed. Petrópolis: Vozes, 2009.

GERMANO, G. D. Instrumento de avaliação metafonológica para caracterização de escolares com dislexia, transtorno e dificuldades de aprendizagem. 2011. 217 p. Tese (Doutorado em Educação)-Faculdade de Filosofia e Ciências da Universidade Estadual Paulista Júlio de Mesquita Filho, Marília, 2011.

JOSÉ, E. da A.; COELHO, M. T. Problemas de aprendizagem. 12. ed. São Paulo: Ática, 2004.

MANUAL DIAGNÓSTICO E ESTATÍSTICO DE TRANSTORNOS MENTAIS. DSM.IV.TR. Tradução Claudia Dornelles. 4. ed. rev. Porto Alegre: Artmed, 2002.

MARTINELLI, S. de C. Os aspectos afetivos das dificuldades de aprendizagem. In: SISTO, F. et al. Dificuldades de aprendizagem no contexto psicopedagógico. 2. ed. Petrópolis: Vozes, 2001.

MEIRA, M. E. M. Para uma crítica da medicalização na educação. Revista Semestral da Associação Brasileira de Psicologia Escolar e Educacional, São Paulo, v. 16, n. 1, p. 135-142, jan./jun. 2012.

MOOJEN, S.; FRANÇA, M. Dislexia: visão fonoaudiológica e psicopedagógica. In: ROTTA, N. T. et al. Transtornos da aprendizagem: abordagem neurobiológica e multidisciplinar. Porto Alegre: Artmed, 2006.

OSTI, A. As dificuldades de aprendizagem na concepção do professor. 2004. 149 p. Dissertação (Mestrado em Educação)-Faculdade de Educação da Universidade Estadual de Campinas, Campinas, 2004.

PASSERI, S. M. R. R. O autoconceito e as dificuldades de aprendizagem no regime de progressão continuada. 2003. 179 p. Tese (Doutorado em Educação)-Faculdade de Educação da Universidade Estadual de Campinas, Campinas, 2003.

PATTO, M. H. S. A produção do fracasso escolar: histórias de submissão e rebeldia. 3. ed. São Paulo: Casa do Psicólogo, 2010. 
PELEGRINI, R. M.; GOLFETO, J. H. Problemas de aprendizagem: um enfoque em psiquiatria infantil. In: FUNAYAMA, C. A. R. (Org.). Problemas de aprendizagem: enfoque multidisciplinar. Campinas: Alínea, 2000.

PEREIRA, K. R. C. Diagnóstico de dificuldade de aprendizagem: construção, concepções e expectativas. 2011. 186 p. Dissertação (Mestrado em Educação)-Faculdade de Educação da Universidade de Brasília, Brasília, DF, 2011.

PEREIRA, A. S. Fracasso escolar: aqui também o mito. Ciências Humanas, Criciúma: FUCRI/UNESC, v. 2, n. 1, jan./jun. 1996.

PIAGET, J. Como a criança pensa: a Psicologia de Piaget e suas aplicações educacionais. Tradução Ruth M. Beard. 10. ed. São Paulo: Theor, 1993.

PIAGET, J. O nascimento da inteligência na criança. Tradução Álvaro Cabral. 2. ed. Rio de Janeiro: Zahar Editores, 1975.

RAUPP, R. S. Docência e dificuldades de aprendizagem: tomada de consciência da ação didático-pedagógica. 2008. 90 p. Dissertação (Mestrado em Educação)-Faculdade de Educação da Universidade Federal do Rio Grande do Sul, Porto Alegre, 2008.

SCHIAVONI, A. Dificuldades de aprendizagem em escrita e percepção de alunos sobre expectativas de professores. 2004. 61 p. Dissertação (Mestrado em Educação)-Faculdade de Educação da Universidade Estadual de Campinas, Campinas, 2004.

SISTO, F. F. Dificuldades de aprendizagem. In: SISTO, F. F. Dificuldades de aprendizagem no contexto psicopedagógico. 2. ed. Petrópolis: Vozes, 2001.

SOUZA, M. P. R. de. Reflexões sobre a atualização psicológica frente ao fracasso escolar. In: SILVA, L. da S; AZEVEDO, J. C. de. (Org.). Reestruturação curricular: teoria e prática no cotidiano da escola. Petrópolis: Vozes, 1995.

TAFNER M. A.; FISCHER, J. Manga com leite mata: reflexões sobre os paradigmas de educação. Indaial, SC: Ed. Asselvi, 2001.

VIÉGAS, L. M. D. C. Uma possibilidade para a superação das dificuldades na aprendizagem da linguagem escrita: o texto e sua reescrita. 2007. 212 p. Dissertação (Mestrado em Educação)-Universidade Federal de Mato Grosso do Sul, Campo Grande, 2007.

VYGOTSKY, L. S. A formação social da mente. Rio de Janeiro: Martins Fontes, 1991. 
VYGOTSKY, L. S. Obras escogidas V: fundamentos da defectología. Tradução Júlio Guillermo Blank. Madrid: Visor, 1997.

VYGOTSKY, L. S. Pensamento e linguagem. Rio de Janeiro: Martins Fontes, 2001.

Recebido em: 30 de março de 2015. Aceito em: 15 de setembro de 2015.

Endereço para correspondência: Avenida Universitária, 1105, Universitário, 88806000, Criciúma, Santa Catarina, Brasil; asp@unesc.net 